\title{
Discussion on Moral Education in the Era of Big Data
}

\author{
Xi Fang, Mengwen Pan \\ 1. School of Philosophy and politics Law, Yunnan Normal University, Kunming650500, China; \\ 2. School of Yunnan language and cuture, Yunnan Normal University, Kunming650500, China; \\ aE-mail: fangxi1982@126.com; b77071393@qq.com
}

\begin{abstract}
The purpose of this study is to improve the effectiveness of moral education under the background of big data era,and take high moral values establishment and people cultivation as the fundamental task of education.This paper first interprets the basic concepts of moral education in big data era, and then analyzes the negative impact on moral education.Finally, it deeply analyses the inevitable choice of moral education in the era of big data.The study concludes that under the background of big data era, moral education should combine with its own characteristics,screen favorable conditions brought by big data era and innovate methods of moral education to realize personalized moral education, also continuously improve the effectiveness development of moral education.
\end{abstract}

Keywords—Big Data; Moral education; Discussion

\section{INTRODUCTION}

Big data impact people's life style, behavior mode and the way of thinking, then profoundly affect people's ideological and political consciousness, value scale,the formation and development of moral concept.It challenges the "authority" and "dominance" of traditional moral education. The imformation is dazzling and changeable,on the one hand,it will have a strong impact on people's existing moral concept, and on the other hand, it will instilled people's new moral concept. This new moral concept can be a double-edged sword for social development. Meanwhile, the overall development of people will also face challenges, such as the crisis of moral belief, the reverse of moral consciousness, the constant conflict of moral norms, and so on. Faced with these shocks, the concept, content, mode and space of moral education have changed. Therefore, contemporary moral education must respond promptly to this change [1].

\section{THE BASIC CONCEPT OF MORAL EDUCATION IN THE ERA OF BIG DATA}

"Big data" is both strange and familiar for most people. What is the "big data"? At present, there is no unified conclusion of relevant experts and scholars here and abroad, For example, Wikipedia defines big data as information; DC defines big data as data form; Gartner defines big data as information assets; McKinsey Global Institute defines big data as data groups that are larger than traditional database software tools in terms of grasping, storage, management and analysis capabilities. According to the definition of EMC, "Big" in big data refers to large data sets, generally in the size of 10TB;Users put these data sets together to form PB level data;

[Foundation item] This paper is a periodical achievement of the National Social Science Fund youth project "The debate and significance of the contemporary Western Virtue Ethics and normative ethics" (project number: 17CZX054)
At the same time, these data come from a variety of data sources, and are implemented in a real-time, iterative manner.(1)Tu ZiPei thinks "Big data means that the size has gone beyond the traditional scale, and the general software tools are difficult to capture, manage and analyze data"; 'big data' is not just 'big capacity'. Greater significance lies in: Human can analyze and use 'data' in a large number, through the exchange, integration and analysis of these data, human can discover new knowledge, create new value, bring 'big knowledge', 'big science and technology', 'big profit 'and 'big development'."(2) Nevertheless, there is a definition of big data in Big Data: A Revolution That Will Transform How We Live, Work, and Think, written by Victor Mayer and Kenneth Kukye," an unprecedented way, through the analysis of massive data, will get products and services with great value, or profound insight."That is to say, big data based on analyzing a large amount of data and massive information, from which we obtain more practical reports to guide people's social practice. It helps people to make correct judgments and choices and guide development in a favorable direction. Big data is like a microscope that we observe the behavior of human beings, greatly expanding the breadth and depth of human observation of their own behavior [2]. At the same time, along with the development of relevant software analysis technology, it further enhances our ability to analyze our own behavior, and enhance the extent of the information from the analysis of its impact on themselves.

The so-called era, refers to the historical period according to the economic, political, cultural and other conditions.(3)In the long history of human social development, with the tool as a symbol, with the progress and change of tools, the development of human society has gone through different times. Big data era refers to the new historical period of the development of human society marked by big data as the core technology, management, application and research. Moral education in the era of big data is the thought of moral education by classical writers of Marxism, Taking the thought of moral education in the theory of Chinese marxist as an important theoretical basis and theoretical support, following the socialist culture with Chinese characteristics and the socialist core value system as the leading role, inherits the traditional Chinese culture, and also draws on and absorbs the positive factors of the world's excellent culture, it condenses the power of society, school and family moral education, condenses the power of moral education in the virtual world and the real world, So as to form a larger and newer moral education that conforms to the characteristics of the big data era. The main contents include: moral cognition education, 
moral emotion education, moral will education and moral behavior education. Specifically speaking, moral cognition education refers to the development of the moral cognition level of the educated, In order to make it master moral truth, guide their own social practice, so as to further promote the development of their moral emotion, moral will, help the educated to develop good moral behavior habits. Moral emotion education is the education of moral reason, it is also the repeated appearance and accumulation of moral emotion, the continuous experience and training of moral emotion, the continuous purification and promotion of moral empathy, it is an important guarantee of the overall quality of moral emotion of the subject in the network society and real society. Moral will education refers to the conscious moral will quality education of the educated, Moral will education refers to the conscious quality education of the moral will of the educated, which enables the educated to have a rational understanding of the corresponding purpose, means, behavior result and value. Realization in the process of behavior occurrence and development. Moral education is moral behavior to guide the educated either in reality or in the network world, all have good value [3]. It needs to consider the subjective initiative of the educated, the education in the subjective understanding of what behavior is the right way, to understand the specific reality of its own place and the virtual environment, understand the mainstream values of social reality and the network society, moral principles and moral responsibility.

\section{NEGATIVE IMPACT OF BIG DATA ErA ON MORAL EDUCATION}

Through the above, big data era is a complex network that consists of Internet, mobile Internet, industrial Internet, sensor networks, Internet of things, artificial intelligence and so on ,its impact on contemporary is not only from technology, but also the way of life, the way of thinking, the way of behavior and even the values of ethics and morality. A new society is constructed in the era of big data. This new society is virtual, open, interactive and public, it brings a series of shocks to contemporary moral education. In general, the negative impact is mainly reflected in the following three aspects.

First, in the era of big data, people's moral behavior tends to be random, blind and irrational. With the continuous improvement of China's market economic system, "Money worship" is in vogue, interest becomes the standard of moral evaluation. In the era of big data, the network information resources are not limited by national, regional, religious, ethnic, ethnic, cultural and social systems, and often unbound by moral standards such as good and evil, justice and injustice. There is a strong contradiction between the super regional nature of information transmission mode and the regional characteristics of information content itself, this contradiction is likely to trigger suspicion and rejection of the fragile reality of moral norms by people who are money-oriented and morally weak. At the same time, the pan-internet brought by big data makes it possible for users to connect with the Internet anytime and anywhere through the application software. Speeding up the development of network technology and flood of network information deconstruct the structure of moral cognition, changing people's cognitive content and cognitive style makes people's moral feelings more easily aroused in the generalization of the network, and the expression is also more networked and data oriented. Under the combined action of the nihility of the real moral environment and the virtualization of the network space, people's moral behavior becomes simpler, fast, low cost, but also tends to be random, blind and irrational.

The second is the era of big data, people's traditional moral concept is lack of appeal. Through big data technology, network space data sharing platform, "rapid consumption" spread rapidly in the network, the moral standards that people encounter are more diverse, the moral cognition is more fragmented, and the moral standards are more individualized, in this unfettered moral market brought about by the age of big data, we can pick up the moral view which conforms to our own value orientation by virtue of the so-called self value.Thus, under the instigation of individuality, the traditional moral concept is less appealing in the virtual society, the traditional way of moral education is less attractive, and the traditional moral education is less convincing. Moreover, massive moral information is "transmitted through the socialization of 'all people for all"', (4) after reading through different gatekeepers, it amplifies and spreads in a wider population. In many times of repeated transmission, may convey to people alienation even the opposite or contrary moral signal, this kind of contrary moral information is more likely to arouse the response and resonance of moral emotion under the instigation of individuality in the young people who advocate individuality. At the same time, in this kind of repeated overlay network communication, moral emotions tend to become indifferent, withdrawn, numb, moral sensitivity decline and passivation, which weakens the appeal of traditional moral concepts.

Third, is the era of big data, multiculturalism makes moral educators authority lost. Negroponte said: "Computing is no longer just about computers, it's going to determine our survival".(6)In the era of big data, the state of social existence has turned from closed to open, and the culture has been development from dominated by one element to and diversified. Nowadays people like to chase new and different, therefore, it is becoming more and more difficult to establish a moral evaluation atmosphere dominated by educators [4]. Conversely, the educated are more willing to accept certain factors that have obvious moral anomie, If the moral anomie factor is internalized into the moral consciousness, moral standard and moral behavior pattern, which is considered to be in line with self judgment, it will have an impact on the moral evaluation atmosphere dominated by educators in the past, it is possible to weaken the perceived trust and respect of educators in the past, and even ignore the moral judgment of educators. Some educators believe in "moral standard pluralism", and advocate respecting everyone's moral choice and moral behavior, think of it as "plural" as long as you don't make a moral assessment of others. The result is that "the common character" of contemporary educators is that their personalities are distinct, and they don't care about the moral judgment of educators, which make the status of educators as moral judges is increasingly dispelled, and the authority of moral educators is losing. 


\section{THE INEVITABLE CHOICE OF MORALITY EDUCATION IN BIG DATA ERA}

First, the use of big data for moral education quantitative research to provide technical support. In the era of big data, the development of technology has broken through the bottleneck of quantitative research, educators can master a large amount of data related to people's emotions and behaviors through technical means. Although the educational process is emotional, it can also be described by quantitative data, the data will produce sound in the quantitative study of moral education, and play a strong supporting role in the research results. This approach is the process of reconstructing the research field on a new basis, it can't simply modify or extend the old research paradigm. This reconstruction is to change the methodology and application of research paradigms, and to change some of the most basic theoretical generalizations in the field of moral education. Big data has created an unprecedented quantifiable dimension, it will inevitably change life, work, thinking in all aspects. In the original field of study, ideas, emotions, etc. are considered to be difficult to achieve quantitative studies, because such studies are constrained by limited data based on hypotheses and sampling surveys [5]. However, in the era of big data, the collection, storage, analysis and application of big data related to moral education will achieve quantitative research. In the future, moral education will change from social science to empirical subject, and big data will become an important cornerstone of moral education in the new era.

The second is to use big data to provide reliable resources for individualized moral education. Personalized moral education in the era of big data is to collect and analyze the moral data of the educated to comprehensively analyze the thought and behavior of the educated, and then realize the active push education, alleviate the dilemma of "information redundancy", in-depth understanding of the individual needs of the educated. Among them, data mining technology is one of the core technologies to realize individualized moral education. For example, by collecting, analyzing and dealing with the data of the audience browsing the website, a model of behavior and interest is established, these models can be used to help educators understand the behavior of the educated. For educators, ubiquitous sensors can sense the education situation, identify the characteristics of the educated, provide appropriate education resources, reasonable arrangement of time and place, record education process and evaluate education effect, provide educators with convenient educational interaction tools, to grasp the interest characteristics and learning needs of the educated, and to promote the realization of personalized education. For the educated, they can choose their own learning content, ways, resources, and partners, the educational environment is also more intelligent, and the popularity of various intelligent terminals can also provide ubiquitous learning tools and learning environments, rich content of educational resources cloud center, greatly meet the personalized needs of the educated.

The third is to use big data to provide important basis for education prediction and learning trend analysis. Browsing records every time in the Internet will become an important basis for big data analysis of related relationships, collect, integrate and analyze these seemingly unrelated tedious data, and establish the correlation, so as to realize the prediction. Correlation is the key to prediction, moral learning in big data environments has the "super power" to building correlation and predicting the future. In the era of big data, the prediction of moral education "super power" is mainly embodied in one kind of "explicit prediction on line". For example, Chinese teen online, Chinese children's network, Chinese Young eagles website, Encouraging learning website and other related websites all are good online moral learning platforms, which include moral ideas, hot news, aphorisms, traditional virtues, etc. Every click of a mouse is the production of moral learning data, gathering these generated data and analyzing the correlations between them can be used to prepare for predictions. Another is "implicit prediction under the line". For example, colleges and universities set up special moral learning base, psychological counseling room, moral problems research institute, etc., collecting the moral issues and moral focus of college students in college, using professional knowledge to integrate and analyze, it can also provide a basis for the prediction of College Students' Moral Learning.

\section{CONCLUSION}

The growing technology and methods has brought a new era of "big data" to the world. Under the background of big data, the moral education is a complicated project and an important part of the fundamental cultivation task, it has an important significance to improve the effectiveness of moral education and cultural power. The big data era appears like a great monster, it has a series of negative effects on contemporary moral education. If people are forcibly separated from new things and new technologies, they will probably exclude moral education, thus leading to a more weakened moral education and a more serious moral crisis. Therefore, taking advantage of technology in big data era to serve the contemporary moral education. The effective combination between moral education and big data has become the inevitable choice of moral education in big data era.

\section{ACKNOWLEDGMENT}

[About the author] Xi Fang (1982- ) Male, Tongshan Hubei people, associate Professor of School of philosophy and politics law, Yunnan Normal University, master supervisor, doctor of philosophy, mainly engaged in Western Ethics Research. Mengwen Pan (1990- ), Female, Yibin Sichuan people, corresponding author teacher of School of Yunnan language and cuture Yunnan Normal University, doctoral candidates in Zhongnan University of Economics and Law, Mainly engaged in the study of Marx's Ethics.

\section{REFERENCES}

[1] Jiang Jiping,"The arrival of the era of big data", China Internet Weekly, vol2, 2012, pp.6-8.

[2] Tu Zipei, "Big data: the coming data revolution", Nanning: Guangxi Normal University press, 2013, pp.57.

[3] Xinhua Dictionary (Revised Edition 2001), Beijing: The Commercial Press,2001, pp.892.

[4] Wang Xianqing,"Whether morality can be virtual -- a moral study of contemporary youth network behavior" Shanghai: Fudan University press, 2011, pp.24.

[5] Nicholas Negroponte,"Digital survival", Hu Yong, Fan Haiyan's Translation, Haikou:Hainan Publishing House, 1997, pp.15. 